\title{
TRADE-OFFS RELATED TO ECOSYSTEM ENGINEERING: A CASE STUDY ON STIFFNESS OF EMERGING MACROPHYTES
}

\author{
T. J. Bouma,,${ }^{1,3}$ M. B. De Vries, ${ }^{2}$ E. Low,${ }^{1}$ G. Peralta,${ }^{1}$ I. C. TÁnczos, ${ }^{2}$ J. van de Koppel, ${ }^{1}$ \\ AND P. M. J. HERMAN ${ }^{1}$ \\ ${ }^{1}$ Netherlands Institute of Ecology (NIOO-KNAW), Centre for Estuarine and Marine Ecology, P.O. Box 140, \\ 4400 AC Yerseke, The Netherlands \\ ${ }^{2}$ WL|Delft Hydraulic, P.O. Box 177, 2600 MH Delft, The Netherlands
}

\begin{abstract}
Biologically mediated modifications of the abiotic environment, also called ecosystem engineering, can significantly affect a broad range of ecosystems. Nevertheless, remarkably little work has focused on the costs and benefits that ecosystem engineers obtain from traits that underlie their ecosystem engineering capacity. We addressed this topic by comparing two autogenic engineers, which vary in the degree in which they affect their abiotic environment via their physical structure. That is, we compared two plant species from the intertidal coastal zone (Spartina anglica and Zostera noltii), whose shoots are exposed to similar currents and waves, but differ in the extent that they modify their environment via reduction of hydrodynamic energy. Our results indicate that there can be trade-offs related to the traits that underlies autogenic ecosystem engineering capacity. Dissipation of hydrodynamic forces from waves was roughly a factor of three higher in vegetation with stiff leaves compared to those with flexible leaves. Drag was highest and most sensitive to hydrodynamic forces in stiff vegetation that does not bend with the flow. Thus, shoot stiffness determines both the capacity to reduce hydrodynamic energy (i.e., proxy for ecosystem engineering capacity) and the drag that needs to be resisted (i.e., proxy for associated costs). Our study underlines the importance of insight in the trade-offs involved in ecosystem engineering as a first step toward understanding the adaptive nature of ecosystem engineering.
\end{abstract}

Key words: autogenic ecosystem engineers; current velocity; drag; extended phenotype; niche construction; sediment accretion; Spartina anglica; trade-offs; waves; Zostera noltii.

\section{INTRODUCTION}

Many organisms have a marked influence on their environment, by consuming resources, by occupying space, or by modifying the physical or chemical properties of their environment. Biologically mediated modifications of the environment are often referred to as ecosystem engineering when those modifications are distinct from and relatively large compared to abiotic processes (Jones et al. 1994, 1997, Reichman and Seabloom 2002). Although there is some debate on the definition of engineering, it is now well recognized that modification of habitats by organisms and its consequences for neighboring organisms is an important process that deserves more attention in general ecological theory (e.g., see Bruno et al. 2003). Ecosystem engineering has been found to significantly affect a broad range of ecosystems (see Jones et al. 1994 for an overview). This is most clearly illustrated in case of invasive ecosystem engineers, which by habitat modification can have a cascading effect on the resident biota

Manuscript received 18 October 2004; revised 17 December 2004; accepted 4 January 2005. Corresponding Editor: C. Martinez del Rio.

${ }^{3}$ Present address: Netherlands Institute of Ecology, Centre for Estuarine and Marine Ecology, P.O. Box 140, 4400 AC Yerseke, The Netherlands. E-mail: t.bouma@nioo.knaw.nl (see Crooks 2002 for an overview). These kinds of observations demonstrate that many engineers can function as keystone species (cf. Jones et al. 1994).

Jones et al. (1994, 1997) distinguished two types of ecosystem engineering. In autogenic engineering the organisms change the environment via their own physical structures and are thus part of the engineered habitat (e.g., trees in a forest), whereas in allogenic engineering organism transform living or nonliving materials from one physical state to another (e.g., dam creation by beavers). In addition to this mechanistic classification, ecosystem engineering can also be classified based on the presence or absence of a positive feedback loop (Jones et al. 1994, 1997). Ecosystem engineering can be regarded as accidental when it has no implications on population growth of the engineering species. However, a positive feedback may exist if the growth of the organism is positively affected by its engineering. The latter is referred to as extended phenotype engineering (Jones et al. 1994, 1997) as such positive feedback has direct consequences for the fitness of the engineer (cf. Dawkins 1982). According to Jones et al. (1994), the "evolutionary effects of extended phenotype engineering, other accidental engineering, and of organisms in the engineered habitat upon the engineer are far from straightforward, and 
generally unstudied," which is further underlined by Odling-Smee et al. (2003). A first exploration into this direction would benefit from a relatively simple and straightforward approach. Strategies of species have been successfully related to trade-offs associated with these strategies, in order to understand its implications for growth and fitness (Pianka 1970, Grime 1977, 1979, 1988, Grime and Mackey 2002). Accordingly, generating knowledge on trade-offs associated with ecosystem engineering would enhance our understanding of ecosystem engineering as a strategy. Hence, it is essential to study the benefits and costs associated with traits that underlie ecosystem engineering by comparing species that share a similar environment, but that vary in the extent to which they modify abiotic conditions.

Intertidal coastal environments offer an excellent model system to perform comparative analysis on ecosystem engineers. Mudflat-salt marsh boundaries offer hostile environment for plant growth, and ecosystem engineering and positive interactions were found to be particularly important in this habitat (e.g., see Bertness and Hacker 1994, Castellanos et al. 1994, Bertness and Leonard 1997, Bruno 2000, Sanchez et al. 2001). In the pioneer zone of salt marshes, stresses by hydrodynamic forces such as wave energy and current velocity play a dominant role in the establishment, survival and expansion of plants (e.g., see Bruno 2000, Houwing 2000, Robbins and Bell 2000, van Katwijk and Hermus 2000). It is obvious that in more extreme parts of this environment, there will be constraints on the capacity of ecosystem engineers to successfully modify their environment. Consequently, the intertidal pioneer zone allows us to identify trade-offs related to traits that underlie ecosystem engineering capacity by comparing species with a relatively limited ecosystem engineering capacity to species with a relatively large ecosystem engineering capacity, but that both have to cope with the same type of abiotic stress.

The lowest zone of coastal salt marshes in the southwest Netherlands is inhabited by two clonal autogenic ecosystem-engineering species that grow closely together at an almost similar height along the elevational gradient: the emergent macrophyte Spartina anglica and the seagrass species Zostera noltii. Spartina anglica is a well-described example of an ecosystem engineer that expands its habitat by enhancing sediment accretion (Castellanos et al. 1994, Sanchez et al. 2001), whereas seagrass species like Zostera noltii also enhance particle accretion and retention which may serve as a source of nutrients (Koch 2001). Although these species are exposed to similar waves and currents, they show a remarkably contrasting growth form: shoots of Spartina are much stiffer than those of Zostera. These differences in growth form reflect differences in physiology, with Zostera being an aquatic species that has to tolerate ebb periods, vs. Spartina being a terrestrial species that has to withstand regular flooding (e.g., see
Bouma et al. 2002). The morphological differences between these species are likely to have strong consequences for their capacity to enhance sediment accretion and retain particles by attenuating hydrodynamic forces. Whereas the effect of vegetation on hydrodynamics has been extensively studied both in the field and in flumes (e.g., see Allen 2000, Verduin and Backhaus 2000, Koch 2001, Abdelrhman 2003 and references therein), little work has been done on the costs and benefits of contrasting shoot morphologies in relation to hydrodynamics. For example, particularly few studies have focused on the consequences of shoot morphologies for withstanding hydrodynamic drag by plant species such as Spartina (e.g., see Ennos 1999, SandJensen 2003 and references therein), especially when compared to the extensive amount of literature on macro algae (e.g., see review of Denny and Gaylord 2002).

In this study, we present a comparative study in which we investigate if the plant trait shoot stiffness involves a trade-off between the ability for habitat modification by reducing hydrodynamic energy from waves or currents, and the costs related to withstanding such hydrodynamic forces. Because ecosystem engineering by plants in stressful intertidal environments centers around amelioration of the physical conditions, insight in trade-offs related to ecosystem engineering must come from understanding underlying physical relationships. Therefore, we identified quantitatively in a series of flume studies how shoot stiffness affects (1) the capacity of a plant species to attenuate wave energy, which we consider as a quantitative proxy for plant benefits associated with ecosystem engineering, and (2) the hydrodynamic drag forces that a plant species has to withstand, which is a proxy for plant costs (a detailed rationale is given in the Materials and methods: Using drag as proxy for costs and wave attenuation as proxy for benefits). Although the hydrodynamic conditions tested in the flume studies were dimensioned to typical scales observed in northwestern European estuarine marshes (Bouma et al., in press), the main aim of the flume study was to identify general mechanisms that are applicable for a relatively broad range of conditions. In addition to Zostera noltii and Spartina anglica vegetation, we also used artificial vegetation made from straight strips of contrasting stiffness. Previous studies indicate that without such simplification, effects of density vs. morphology may be hard to disentangle (Fonseca and Cahalan 1992). Implications of trade-offs related to traits that underlie ecosystem engineering capacity are subsequently discussed in a broad context.

\section{Materials And Methods}

\section{The experimental species}

In many northwestern European salt marshes, Spartina anglica and Zostera noltii grow adjacently at the lowest parts of the vegetated intertidal areas. Because of wave attenuation (e.g., see Fonseca and Cahalan 
1992, Yang 1998, Koch and Gust 1999, Moller et al. 1999) and/or reduced current velocities (e.g., see Fonseca et al. 1982, Gambi et al. 1990, Leonard and Luther 1995, Shi et al. 1995, Widdows and Brinsley 2002, Abdelrhman 2003), sediment is known to settle within those vegetations. This has been well documented for Spartina, where this process over time leads to the formation of dome shaped tussocks (Castellanos et al. 1994, Sanchez et al. 2001), but also for other salt marsh species (e.g., see Yang 1998). By lateral expansion, the dome shaped Spartina tussocks eventually can merge into closed vegetation. Although many reports stress the importance of plant-induced sedimentation and reduced erosion in seagrass meadows (e.g., see Almasi et al. 1987, Gacia et al. 1999, Granata et al. 2001, Koch 2001, Madsen et al. 2001), there are to our knowledge no reports of clearly elevated Zostera noltii patches that resemble the dome-shaped tussocks described for Spartina.

\section{Using drag as proxy for costs and wave attenuation as proxy for benefits: a rationale}

Drag force was used as a quantitative proxy for the costs associated to shoot stiffness. The rationale behind this is that having to withstand strong drag forces will either put requirements on tissue construction and shoot anchoring or result in enhanced risk of breaking and/ or washing away. Acceleration forces were not studied, as Gaylord (2000) demonstrated convincingly that in the surf zone, the maximum observed forces are closely related to calculated drag forces, and that large acceleration forces were not commonly imposed on surfzone organisms. Inertial forces were not studied, as Denny (1999) in an overview paper explicitly underlined that inertial forces are only relevant to organisms that are large enough to have both a considerable mass, and a sufficient length of flexible "tether" to allow that mass to get up to speed (see also Denny et al. 1998). These criteria are unlikely to apply to flexible organisms with a morphology like that of Zostera noltii, which consists of short light leaves. Drag force was measured as function of both currents and waves.

Reduction of hydrodynamic energy is a prerequisite for ecosystem engineering by enhancing sediment accretion. Hence, reduction of hydrodynamic energy was used as a quantitative proxy for the benefits that may be associated to increased shoot stiffness and shoot density. Reduction of hydrodynamic energy was measured as wave attenuation. We did not study unidirectional flow as it is well established that velocities are strongly reduced in all types of dense vegetations, regardless of their stiffness (e.g., see Fonseca et al. 1982, Gambi et al. 1990, Leonard and Luther 1995, Shi et al. 1995, Allen 2000, Verduin and Backhaus 2000, Koch 2001, Widdows and Brinsley 2002, Abdelrhman 2003 and references therein). Because of the latter, vegetation height is the most important factor that determines the volume over which hydrodynamic energy from cur- rents is being attenuated, and sediment accretion is enhanced. The height of a vegetation that is exposed to flow (and thus the volume from which sediment will be trapped) is mainly a function of bending, which we quantified in our drag experiments in the unidirectional flow flume.

\section{General field conditions and measurements}

The main objective of our flume studies was to identify general mechanisms that apply to tidal estuarine marshes in northwestern Europe, that are (in contrast to many northeast U.S. marshes) commonly characterized by large sediment accretion rates. Typical conditions for such estuarine marshes are tidal currents ranging from 50 to $400 \mathrm{~mm} / \mathrm{s}$, wave heights ranging from 50 to $500 \mathrm{~mm}$, and tidal inundation at the pioneer zone ranging from 0.5 to $2 \mathrm{~m}$ water on top of the sediment surface. In the Westerschelde estuary (southwestern Netherlands), we observed that the elevation where the pioneer vegetation occurs is positively related to the length of the wind fetch facing the marsh. Our most elaborated source of information on hydrodynamic conditions in these type of tidal estuarine marshes was obtained from a long-term (months) highresolution $(4 \mathrm{~Hz})$ hydrodynamic database collected at several locations at a mudflat-salt-marsh ecosystem at the Paulinapolder in the Westerschelde estuary (southwestern Netherlands; Bouma et al., in press). Velocity measurements on the mudflat just in front of the vegetation, showed that from June to October current velocities were proportional to tidal amplitude, and ranged between 50 and slightly over $300 \mathrm{~mm} / \mathrm{s}$. During one spring tide week in August and one spring tide week in September, dissipation of wave energy was measured along a 50-m transect perpendicular to the fringe of the Spartina vegetation, starting $1 \mathrm{~m}$ into the mudflat. Due to the relatively sheltered location of the Paulinapolder salt marsh, waves were small. During both measuring periods, the wave heights were on average around $50 \mathrm{~mm}$, but we visually observed larger waves in less sheltered marshes. Whereas present flume conditions will not be an exact representation of all tidal estuarine marshes in northwestern Europe, they are within a range that enables us to identify general principles with respect to the effect of plant characteristics on wave attenuation and drag. In this study, the data from the 50-m transect at the Paulinapolder salt marsh were used to test if wave attenuation in the flume and field had a similar magnitude.

\section{Wave attenuation in the flume (as a proxy for benefits to the plant)}

The effect of natural and artificial vegetation (see Materials and methods; Plant material, plant mimics, and the number of structures) on wave height was quantified in a wave flume tank at WL|Delft Hydraulics (Delft, The Netherlands). We applied regular waves with a wave height of $50 \mathrm{~mm}$ and a period of $1 \mathrm{~s}$, which 


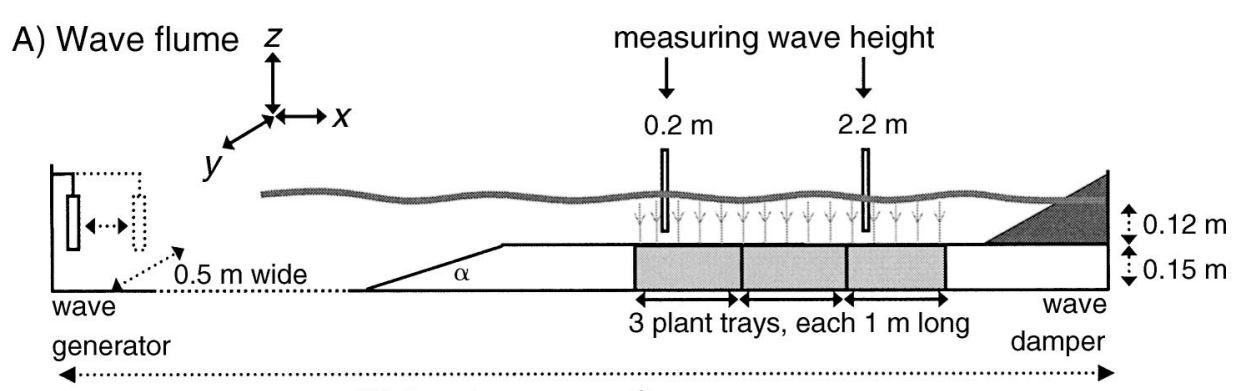

13.5 m long wave flume

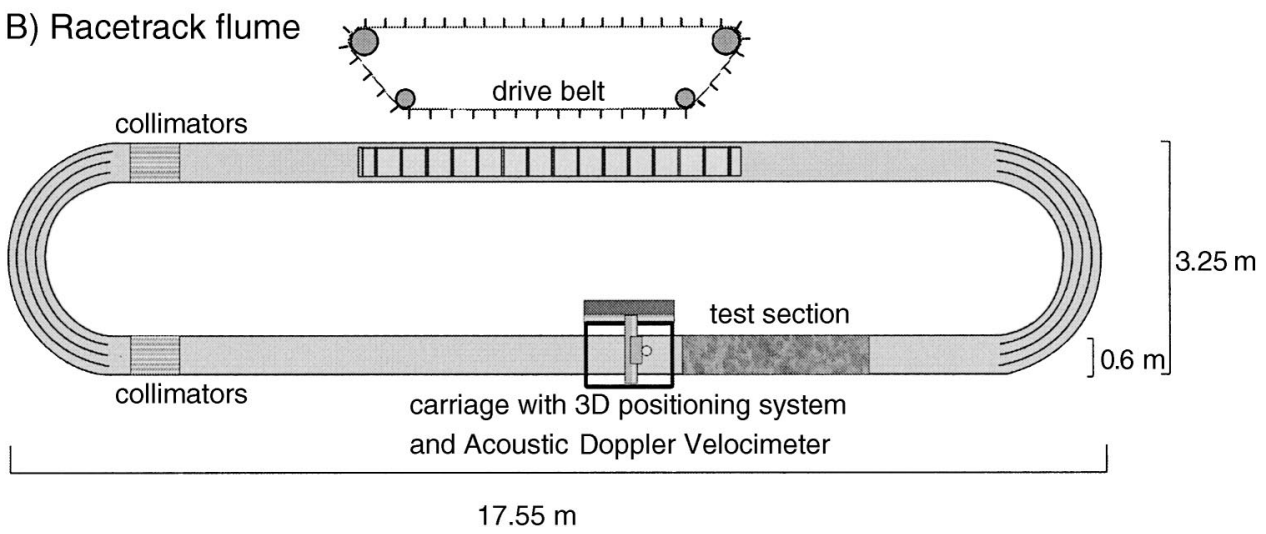

FIG. 1. Schematic representation of (A) the flume used to study wave attenuation and drag due to waves and (B) the racetrack flume used for studying drag due to unidirectional flow. The Acoustic Doppler Velocimeter was manufactured by Nortek AS, Oslo, Norway.

was rather comparable to the waves measured at the Paulinapolder mudflat-salt-marsh ecosystem (i.e., around $50 \mathrm{~mm}$ high) and matched the ability of the wave generator and the dimensions of the flume. The flume tank channel had a total horizontal distance of $13.5 \mathrm{~m}$, the working section of which began at $8.08 \mathrm{~m}$. The horizontal distance of the section with plants was 3 m (Fig. 1). Regular waves were generated by a piston and at the opposite end of the flume dampened by a wooden rack. Wave height was measured with two conductivity meters, one at the beginning $(0.2 \mathrm{~m})$ and one further $(2.2 \mathrm{~m})$ into the vegetation (Fig. 1). At both locations, measurements were taken at $20 \mathrm{~Hz}$ over a period of at least $720 \mathrm{~s}$. The wave flume was filled with $120 \mathrm{~mm}$ water on top of the sediment. We choose to match the flooding depth with the height of the vegetation that we grew in our climate room $(\sim 100 \mathrm{~mm}$; see Materials and methods: Plant material, plant mimics, and the number of structures) to maximize the ability to quantify differences in vegetation effects on wave attenuation. That is, higher water heights will diminish the wave attenuating effect of the vegetation, whereas lower water heights will enhance the effect of the bottom. Although this experimental design is a simplification of all possible field conditions, it generates mechanistic insight in the importance of shoot stiffness and shoot density for wave attenuation.

\section{Drag measurements in the flume}

(as a proxy for costs to the plant)

Drag was measured as the force present at the base of the stem, while exposing natural and artificial plants of known dimensions (see Materials and methods: Plant material, plant mimics, and the number of structures) to a range of velocities from 50 to $370 \mathrm{~mm} / \mathrm{s}$ in a unidirectional flow flume (Fig. 1; description available online $),{ }^{4}$ or to regular waves with a wave height of $50 \mathrm{~mm}$ and a period of $1 \mathrm{~s}$ in the wave flume described above (see Materials and methods: Wave attenuation in the flume). The water height on top of the sediment was $400 \mathrm{~mm}$ in the unidirectional flow flume (i.e., to allow for a well developed velocity profile) and $120 \mathrm{~mm}$ in the wave flume (i.e., to resemble the aforementioned wave attenuation experiments). The base of the stem was connected to the attachment point of a force transducer that was developed by WL|Delft Hydraulics (Delft, The Netherlands). The force transducer (cf. Denny 1988, Carrington 1990) consists of a stiff solid platform, carried by two steel cantilever beams, with four temperature-corrected strain gauges mounted in pairs on opposite sides of each of the two steel cantilevers. The construction of the force transducer compensates for bending moment, so that the voltage

\footnotetext{
${ }^{4}\langle$ www.nioo.nl/science/facilities/flume/flume.htm〉
} 
TABle 1. Plant characteristics and observed wave heights in the flume experiment on wave attenuation.

\begin{tabular}{|c|c|c|c|c|c|}
\hline \multirow[b]{3}{*}{ Vegetation type } & \multirow{2}{*}{\multicolumn{2}{|c|}{ Density }} & \multicolumn{2}{|c|}{$H_{\mathrm{rms}}$} & \multirow{3}{*}{$\begin{array}{c}\delta h \\
(\mathrm{~mm} / \mathrm{m})\end{array}$} \\
\hline & & & \multirow{2}{*}{$\begin{array}{l}\text { At } 0.22 \mathrm{~m} \\
(\mathrm{~mm})\end{array}$} & \multirow{2}{*}{$\begin{array}{c}\text { At } 2.22 \mathrm{~m} \\
(\mathrm{~mm})\end{array}$} & \\
\hline & $\left(\mathrm{stems} / \mathrm{m}^{2}\right)$ & $\left(\right.$ structures $\left./ \mathrm{m}^{2}\right)$ & & & \\
\hline \multicolumn{6}{|l|}{ Flexible } \\
\hline Flexible strips & 450 & 450 & $32 \pm 0.4$ & $30 \pm 0.2$ & 1.1 \\
\hline Flexible strips & 1850 & 1850 & $32 \pm 0.4$ & $26 \pm 0.3$ & 3.0 \\
\hline Zostera noltii $\dagger$ & 13400 & 13400 & $32 \pm 0.5$ & $18 \pm 0.3$ & 7.3 \\
\hline \multicolumn{6}{|l|}{ Stiff } \\
\hline Stiff strips & 450 & 450 & $33 \pm 0.5$ & $28 \pm 0.4$ & 2.9 \\
\hline Stiff strips & 1850 & 1850 & $32 \pm 0.5$ & $20 \pm 0.3$ & 6.1 \\
\hline Spartina anglica $\ddagger$ & 225 & 395 & $28 \pm 0.5$ & $20 \pm 0.5$ & 3.6 \\
\hline Spartina anglica & 900 & 1575 & $32 \pm 1.5$ & $14 \pm 0.3$ & 9.2 \\
\hline Spartina anglica & 2400 & 4200 & $29 \pm 0.8$ & $7 \pm 0.3$ & 10.8 \\
\hline Spartina anglica§ & 2400 & 4200 & $30 \pm 0.2$ & $6 \pm 0.1$ & 12.0 \\
\hline
\end{tabular}

Notes: In the case of Spartina, we recalculated the number of shoots into the total number of structures that obstruct water, using the number of leaves per stem, the branching angles, and the height where branches are attached to the stem (details are given in the Materials and methods: Plant material, plant mimics, and the number of structures). In the other cases, the number of leaves or strips directly represents the number of structures. Wave attenuation $(\delta h)$ was calculated as the loss of significant wave height $\left(H_{\mathrm{rms}}\right)$ divided by the horizontal distance between wave height measurements within the vegetation $(m): \delta h=\left(H_{\mathrm{rms}}\right.$ at $0.22 \mathrm{~m}-H_{\mathrm{rms}}$ at $2.22 \mathrm{~m}) / 2 \mathrm{~m}$. Error terms are SD.

$\dagger$ Zostera transplanted intact from the field to the flume.

\$ Spartina grown in a greenhouse until the average vegetation reached a height of $\sim 100$ $\mathrm{mm}$.

$\S$ Spartina collected from the field and cut at a height of $\sim 100 \mathrm{~mm}$.

output of the force transducer was linear with forces up to $10 \mathrm{~N}$. Calibration was done in analogy to Stewart (2004). During the drag measurements in the unidirectional flow flume, voltage readings were collected manually. In case of rapid fluttering movements of the stem due to flow separation, the mean value for the voltage reading was estimated by monitoring the readings for $\sim 1 \mathrm{~min}$. We were not able to obtain reliable readings at low velocities (i.e., $<200 \mathrm{~mm} / \mathrm{s}$ ). During the drag measurements in the wave flume, voltage readings were taken at $20 \mathrm{~Hz}$ using a datalogger. From the sinusoidal shape of the fluctuation of drag over time, we extracted the absolute value for the maximum drag that the plants experienced using Delft-Auke-PC software (WL|Delft Hydraulics, Delft, The Netherlands).

Bending of the (artificial) plants (see Materials and methods: Plant material, plant mimics and the number of structures) that were placed in the unidirectional flow flume was quantified by drawing them on a sheet attached to the transparent side of the flume. The angle with the horizontal was then calculated as the arctangent of $\delta y / \delta x$, with $\delta y$ being the vertical distance, and $\delta x$, the horizontal distance between the place of shoot attachment on the force transducer and the tip of the shoot. That is, we simplified the shape of the curve for the bent (artificial) plants, which looked similar to a logarithmic curve, to that of a straight line that can be characterized by a simple angle with the horizontal.

Plant material, plant mimics, and the number of structures

Wave attenuation was measured on vegetation of Spartina anglica and Zostera noltii with different den- sities (Table 1). Vegetation was obtained either from seeds planted in regular patterns (Spartina) or by collecting vegetation from the field (Spartina and Zostera). The cultivated Spartina plants were grown in trays that exactly fitted into the flume (i.e., $1 \mathrm{~m}$ long $\times 0.5 \mathrm{~m}$ wide $\times 0.15 \mathrm{~m}$ high), and measurements were done when stems were $\sim 100 \mathrm{~mm}$ long. The Spartina plants that were collected from the field were transported to the flume, using similar trays as used for cultivation, and were pruned to obtain a length of $\sim 100$ $\mathrm{mm}$ before the experiment started. Zostera plants were collected similarly as described for Spartina, but were not pruned as they were already $\sim 100 \mathrm{~mm}$ long. Different vegetation types are indicated in the results. During the experiments on Spartina, the vegetation was illuminated and the flume was emptied overnight. Zostera plants were also illuminated overnight but kept submerged. At the end of the flume measurements all plants were removed and the number of stems per square meter determined by counting subsamples.

To get a better understanding of how the combination of vegetation stiffness and density affected wave attenuation, we also made measurements on plant mimics of contrasting stiffness, but with identical dimensions (100 mm long, $5 \mathrm{~mm}$ wide). Zostera-like flexible plant mimics were obtained by cutting a plastic folder into strips, whereas tie wraps (cable ties) were used as Spartina-like stiff plant mimics. In the flume experiments, all plant mimics were placed with the $5 \mathrm{~mm}$ wide area directed perpendicular to the current. The selection of mimics was based on the possibility to obtain large enough quantities to generate dense vegetations, com- 


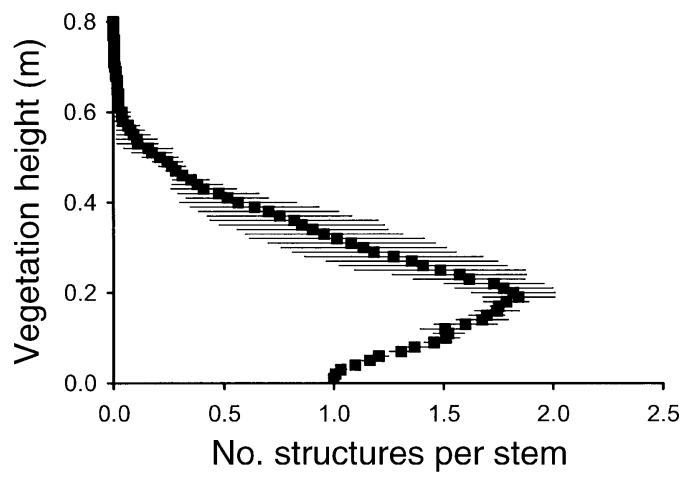

FIG. 2. Schematic representation of the vertical distribution of structures within a mature Spartina vegetation. Values are means $\pm \mathrm{SD}(n=4$ plots of $0.5 \times 0.5 \mathrm{~m})$. A similarly shaped curve is also expected to apply to smaller vegetation, although along another $y$-axis.

bined with their bending behavior when exposed to unidirectional flow. The mimics were not intended to offer a perfect model for the plant species, and do not offer a perfect reflection of all characteristics of the species studied (e.g., tie wraps had small ripples on the down-stream side, and were not round like Spartina stems). However, these kind of deviations are of relatively minor importance when trying to obtain a more general insight in the effect of stiffness on drag forces and the combined effect of stiffness and density on wave attenuation. This is especially true because the difference in shoot stiffness between Spartina and Zostera is relatively large compared to the differences in stiffness between each species and its mimic. As will be shown by our results, flexibility of the structures was the first-order factor determining wave attenuation and drag. The mimics were used in low (450 mimics/ $\mathrm{m}^{2}$ ) and in high $\left(1850 \mathrm{mimics} / \mathrm{m}^{2}\right)$ densities (Table 1).

To derive general insights in wave attenuation across vegetation types, we estimated the number of structures for each vegetation. Such approach is only useful if all structures have dimensions of a similar magnitude, as was the case in our study. In the Zostera meadow and artificial vegetations, the number of structures equals the number of leaves and plastic strips, respectively. For Spartina, a somewhat more elaborate calculation was needed. Destructive harvesting of four plots $(0.5$ $\times 0.5 \mathrm{~m})$ at the Spartina zone of the salt marsh at Paulinapolder (Western Scheldt estuary, southwestern Netherlands) provided information on the number of stems per square meter in natural vegetation. Subsequently, information on plant height, the height where leafs are attached to the stem, and the length of each of these leafs was obtained from a subsample of 40 individual plants per plot. Based on these data, and considering a mean leaf angle $(\alpha)$ of $45^{\circ}$ between the stem and its leaves, the number of plant structures (i.e., stems and leaves), $n(z)$ at height $\mathrm{z}$ above the bottom was calculated for each plant as follows:

$$
\begin{aligned}
n(z)= & \begin{cases}1 & \text { if } H_{p} \geq z \\
0 & \text { if } H_{p}<z\end{cases} \\
& +\sum_{i=1}^{m} \begin{cases}1 & \text { if }\left[H_{1}+L_{1} \cdot \cos (\alpha)\right] \geq z \\
0 & \text { if }\left[H_{1}+L_{1} \cdot \cos (\alpha)\right]<z \\
0 & \text { if } H_{1} \leq z\end{cases} \\
& \text { if } H_{1}>z
\end{aligned}
$$

where $m$ is the number of leafs, $H_{\mathrm{p}}$ is the height of the stem, $H_{1}$ is the height where the leaf is attached to the stem, and $L_{1}$ is the length of the leaf. A mean value for $n(z)$ was then calculated for each of the four plots based on the data determined from 40 individual plants (Fig. 2 ). Based on this vertical distribution of a mature Spartina anglica vegetation, we estimated the number of structures for the Spartina vegetations used in the flume, by multiplying the number of stems with a factor of 1.75 .

Drag measurements were done on a small number of detached Spartina and Zostera shoots that were glued parallel to each other on to a force transducer (Table 2). The Spartina and Zostera shoots used for drag measurements were obtained from climate room cultures. To get a more general understanding of how stiffness affects drag, we also used the plant mimics. We used $5 \mathrm{~mm}$ wide strips made from plastic folders (flexible, to mimic Zostera), tie wraps (cable ties; stiff, to mimic Spartina) and stainless steel (100\% stiff). We attached eight 100 or $200 \mathrm{~mm}$ long strips parallel to each other on the force transducer.

\section{Data analysis}

For the studies in the wave flume, statistics of wave height and period were extracted from the data series using Delft-Auke-PC software developed by WL|Delft Hydraulics. The wave-flume data that we present are based on the estimates of the significant wave height $\left(H_{\mathrm{rms}}\right)$. As we only used regular waves in our flume experiments, $H_{\mathrm{rms}}$ is calculated as the mean (root mean square) wave height (from crest to trough) of all waves in the dataset. For each measurement, at least 720 waves were analyzed. Wave attenuation, calculated as the loss of wave height divided by the horizontal distance between wave height measurements within the vegetation $(\mathrm{m})$ (i.e., $\delta h=\left[H_{\mathrm{rms}}\right.$ at $0.22 \mathrm{~m}-H_{\mathrm{rms}}$ at $2.22 \mathrm{~m}] / 2 \mathrm{~m}$ ) was then plotted against the number of structures (see Materials and methods: Plant material, plant mimics, and the number of structures). Although we chose to present our data on wave attenuation as wave heights, the results can be easily converted to wave energy (see Materials and methods: A brief theoretical background). The latter was used to plot the results of the drag measurements in the wave flume.

\section{A brief theoretical background}

Drag can be divided into two types: profile or form drag, which is due to the low pressure that develops 
TABLE 2. Relationship of current velocity $(U)$ with the drag per unit of frontal surface area $\left(F_{\mathrm{d}}^{\prime}\right)$ and the bending $(\alpha)$ for shoots of contrasting stiffness.

\begin{tabular}{|c|c|c|c|c|c|c|c|c|c|c|}
\hline \multirow[b]{2}{*}{ Vegetation type } & \multirow{2}{*}{$\begin{array}{c}\text { Frontal } \\
\text { area }\left(\mathrm{m}^{2}\right)\end{array}$} & \multicolumn{4}{|c|}{$F_{\mathrm{d}}^{\prime}=x U^{\beta}$} & \multirow{2}{*}{$\begin{array}{c}F_{\mathrm{d}}^{\prime} \text { at } \\
U_{\max } \\
\left(\mathrm{N} / \mathrm{m}^{2}\right)\end{array}$} & \multicolumn{3}{|c|}{$\alpha=90 e^{s U}$} & \multirow{2}{*}{$\begin{array}{c}\alpha \text { at } U_{\text {ma }} \\
\left({ }^{\circ}\right)\end{array}$} \\
\hline & & $x$ & $\beta$ & $R^{2}$ & $n$ & & $s$ & $R^{2}$ & $n$ & \\
\hline \multicolumn{11}{|l|}{ Flexible } \\
\hline Zostera noltii & 0.0032 & $0 \dagger$ & $\dagger$ & $\dagger$ & 6 & 0.2 & -0.0091 & 0.92 & 7 & 4 \\
\hline Flexible (200 mm long) & 0.0080 & 0.0117 & 1.05 & 0.85 & 7 & 5.5 & -0.0066 & 0.79 & 7 & 11 \\
\hline Flexible (100 mm long) & 0.0040 & 0.0405 & 0.91 & 0.49 & 7 & 7.8 & -0.0037 & 0.99 & $5 \ddagger$ & 22 \\
\hline \multicolumn{11}{|l|}{ Stiff } \\
\hline Spartina anglica & 0.0192 & 0.0063 & 1.35 & 0.99 & 7 & 18 & -0.0021 & 0.96 & $6 \ddagger$ & 39 \\
\hline Stiff (200 mm long) & 0.0080 & 0.0205 & 1.31 & 0.95 & 7 & 47 & -0.0015 & 0.96 & $5 \ddagger$ & 49 \\
\hline Stiff (100 mm long) & 0.0040 & 0.00005 & 2.37 & 0.97 & 7 & 54 & -0.0005 & 0.93 & $5 \ddagger$ & 73 \\
\hline Steel (200 mm long) & 0.0080 & 0.0005 & 2.05 & 0.99 & 7 & 90 & $-3 \times 10^{-18}$ & $\S$ & 7 & 90 \\
\hline Steel (100 mm long) & 0.0040 & 0.0033 & 1.67 & 0.96 & 7 & 61 & $-3 \times 10^{-18}$ & $\S$ & 7 & 90 \\
\hline
\end{tabular}

Notes: $F_{\mathrm{d}}^{\prime}$ is the drag per unit frontal surface area $\left(\mathrm{N} / \mathrm{m}^{2}\right)\left(F_{\mathrm{d}}^{\prime}=x U^{\beta}\right), x$ and $\beta$ are fitted parameters, $\alpha=$ angle of the shoot with the horizontal $\left(90^{\circ}\right.$, no bending so that shoot remains in vertical position; $0^{\circ}$, shoot bent horizontally), and $s$ is a parameter fitted while forcing the function through $90^{\circ}$ for $U=0$. Significant correlations are shown with bold type. The values of $F_{\mathrm{d}}^{\prime}$ and $\alpha$ at $U_{\max }$ were measured at the highest velocity $(U ; \mathrm{mm} / \mathrm{s})$ we applied $(370 \mathrm{~mm} / \mathrm{s})$.

$\dagger$ Drag was below the detection limit of the force transducer (i.e., drag values were around zero).

$\$$ Due to less bending of these shoots, we could draw the bending angle for fewer velocities.

$\S$ Fitting of the exponential function is impossible, as the steel strips maintain a vertical position $\left(\alpha=90^{\circ}\right)$ at all velocities.

behind an object due to separation of flow as the fluid moves around the object, and skin or friction drag, which results from viscous shear as a fluid moves over (bent) plant tissues or wetted surface (Denny 1988, Ennos 1999). For a given surface area, friction drag, as present when this surface area is oriented parallel to the flow, is often negligible compared to profile drag, as present if this surface area is oriented perpendicular to the flow. The ability of flexible plants to alter their shape in order to reduce drag by reducing the crosssectional area perpendicular to the flow is often referred to as reconfiguration. Reconfiguration results in complicated mathematics (Alben et al. 2002), which are often addressed by the simplified method described here. In unidirectional flow conditions, the $\operatorname{drag}\left(F_{\mathrm{d}} ; \mathrm{N}\right.$ is equivalent to $\left.\mathrm{kg} \cdot \mathrm{m} \cdot \mathrm{s}^{-2}\right)$ of an object is proportional to a power of the velocity $(U ; \mathrm{m} / \mathrm{s})$ :

$$
F_{\mathrm{d}}=0.5 \rho A_{\mathrm{c}} C_{\mathrm{d}} U^{\beta}
$$

with $\beta=2$ for rigid objects but $\beta<2$ for flexible objects that are able to reconfigure, $\rho$ being the density of seawater $\left(1025 \mathrm{~kg} / \mathrm{m}^{3}\right), A_{\mathrm{c}}$ being the characteristic area of the object $\left(\mathrm{m}^{2}\right)$, and $C_{\mathrm{d}}$ being the drag coefficient (Denny 1988, Sand-Jensen 2003). For blunt objects, the characteristic area of the object should be equal to the projected area, whereas for streamlined objects the use of the wetted surface is more appropriate (Vogel 1994). We present our data as drag per unit of total frontal surface area $\left(F_{\mathrm{d}}^{\prime} ; \mathrm{N} / \mathrm{m}^{2}\right)$, with total frontal surface area defined as the maximal area present in the plane perpendicular to flow (i.e., area as in the absence of current). We regard the drag per unit of this maximum frontal surface area as most relevant for comparing plant growth strategies, as it is an inherent part of such strategy how this total frontal surface area is exposed to currents and waves:

$$
F_{\mathrm{d}}^{\prime}=F_{\mathrm{d}} / A_{\mathrm{c}}=0.5 \rho C_{\mathrm{d}} U^{\beta} .
$$

For regular waves, wave energy $\left(E ; \mathrm{J} / \mathrm{m}^{2}\right)$ is proportional to the square of wave height $(H ; \mathrm{m})$ :

$$
E=(1 / 8) \rho g H^{2}
$$

with $\rho$ the density of seawater $\left(1025 \mathrm{~kg} / \mathrm{m}^{3}\right)$ and $g$ gravity acceleration $\left(9.8 \mathrm{~m} / \mathrm{s}^{2}\right)$ (Denny 1988).

\section{RESULTS}

\section{Identifying plant traits that enable wave attenuation}

Wave height is clearly attenuated by vegetation, with plant stiffness and vegetation density being important variables in explaining the amount of wave energy that is dissipated at a given inundation height (Table 1 and Fig. 3). By combining adjustable plant densities and shoot stiffness with identical shoot dimensions, the plant mimics are an exemplary illustration of how higher stiffness (up to a factor of 2.6) as well as higher density (up to a factor of 2.7) enhances the loss of wave height by increasing the absorption of wave energy (Table 1). The effect of shoot density on wave attenuation becomes even clearer (up to a factor of 6.6) when comparing these artificial vegetations to natural vegetations, which are characterized by much higher densities (Table 1). We did not observe wave attenuation, when a short vegetation $(100 \mathrm{~mm})$ was flooded by $240 \mathrm{~mm}$ of water; only Spartina vegetation of $>240$ $\mathrm{mm}$ long, collected in the field, gave similar wave attenuation at $240 \mathrm{~mm}$ flooding as at $120 \mathrm{~mm}$ flooding (data not shown).

To derive general relationships across vegetation types, we plotted the loss of wave height as a function of the number of structures. This approach is only feasible if all structures have relatively similar dimensions, which was the case in the present study. Based 


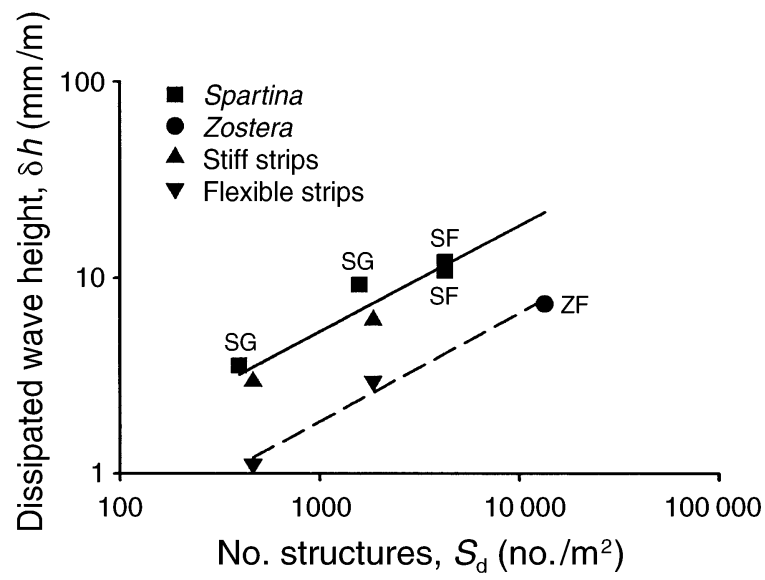

FIG. 3. The reduction in wave height ( $\delta h$; wave height loss per meter of vegetation) as a function of the density of stiff vs. flexible structures $\left(S_{\mathrm{d}}\right)$. The upper regression line $(\delta h$ $\left.=0.127\left[S_{\mathrm{d}}^{0.54}\right] ; R^{2}=0.90\right)$ indicates the wave attenuation in stiff vegetation, whereas the lower regression line $(\delta h=$ $\left.0.041\left[S_{\mathrm{d}}^{0.55}\right] ; R^{2}=0.99\right)$ represents wave attenuation in flexible vegetation. As indicated in the key, regression lines combine vegetation of real plants with those made from artificial leaves. Water height in the wave flume was $120 \mathrm{~mm}$ above the sediment. Key to abbreviations: ZF, Zostera transplanted intact from the field to the flume; SG, Spartina grown in a greenhouse till a height of $\sim 100 \mathrm{~mm}$; SF, Spartina collected from the field and cut at a height of $\sim 100 \mathrm{~mm}$. Note the logarithmic scales.

on Fig. 2, the number of structures for Spartina vegetation was estimated by multiplying the stem density by 1.75 , whereas no multiplication was necessary for other vegetation types (see Materials and methods: Plant material, plant mimics, and the number of structures). Our analysis revealed a distinct relationship for both flexible and stiff vegetation types (Fig. 3). Both lines had an exponent close to 0.55 (i.e., similar slopes), and a difference in their multiplication factors indicating their different shoot stiffness (Fig. 3). We conclude that stiff vegetation is roughly a factor of 3 $(0.127 / 0.041)$ more efficient in absorbing wave energy than flexible vegetation. This result was relatively insensitive to the multiplication factor used to calculate the number of structures in a Spartina vegetation that was derived from Fig. 2; using a multiplication factor of 1.5 instead of 1.75 gives a ratio of $3.3(0.134 / 0.041)$. More importantly than the precise value of this ratio, Fig. 3 clearly demonstrate the fundamental importance of plant stiffness for attenuating waves. Whereas stiff vegetation is visibly vibrating when absorbing the wave energy, flexible vegetations move gently along with the orbital water movement of the waves, allowing most of the energy to pass on. Our results emphasize the importance of both density and stiffness in dissipating wave energy when inundation height is similar to plant height (Table 1 and Fig. 3).

Similar to the flume, field measurements showed strong attenuation of wave energy by the Spartina veg- etation (Fig. 4). Direct comparison of the data is difficult, because of differences in inundation heights, vegetation heights, elevational gradients at the sediment surface (present in the field vs. absent in the flume), and horizontal distance scales. However, field and flume data are consistent in that they illustrate that significant wave attenuation can occur over a short distance in Spartina vegetation. That is, in the field most energy was lost in the first $2 \mathrm{~m}$, which is similar to the horizontal distance between wave height measurements within the vegetation we studied in the flume.

\section{Costs associated to contrasting shoot morphologies}

As explained in the introduction and methods (see Materials and methods: Using drag as proxy for costs and wave attenuation as proxy for benefits: a rationale), drag was used as a quantitative proxy for the costs that may be associated to contrasting shoot morphologies. Stiffness of the aboveground tissues was an important factor explaining differences in drag experienced by the different plants (Figs. 5 and 6) and plant mimics (Fig. 5). The upper regression line in Fig. 5 is obtained for drag measurements at a relative high current velocity $(370 \mathrm{~mm} / \mathrm{s})$, whereas the lower regression line is obtained at a current velocity of $240 \mathrm{~mm} / \mathrm{s}$. Arrows indicate how enhanced velocity results in additional bending ( $x$-axis) vs. enhanced drag ( $y$-axis) for tissues that differ in stiffness. Fig. 5 illustrates three important points:

1) The diverging regression lines indicate that the dependence of drag on current velocity is negligible for easily bending flexible structures (small values for $\alpha)$ and largest for nonbending stiff structures $\left(\alpha=90^{\circ}\right)$. For structures of intermediate stiffness $\left(40^{\circ}<\alpha<80^{\circ}\right)$

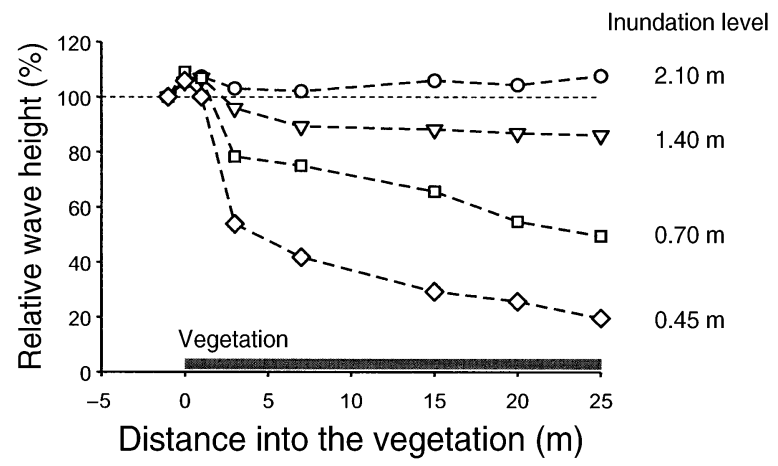

FIG. 4. Wave attenuation observed in natural Spartina vegetation at the Paulina salt marsh in southwestern Netherlands. Wave heights at different positions in the vegetation were expressed as a percentage of the height of the incoming waves, as they varied over time. On average, the height of the incoming waves was $\sim 50 \mathrm{~mm}$. Different symbols represent inundation heights relative to the sediment surface, of $0.45(\diamond), 0.70(\square), 1.40(\nabla)$, and $2.10(\circ) \mathrm{m}$. The mean length of a random mix of young and full-grown stems was $0.35 \pm$ $0.18 \mathrm{~m}(n=192$ stems; $\pm \mathrm{SD})$ with maximum lengths up to $0.9 \mathrm{~m}$. 


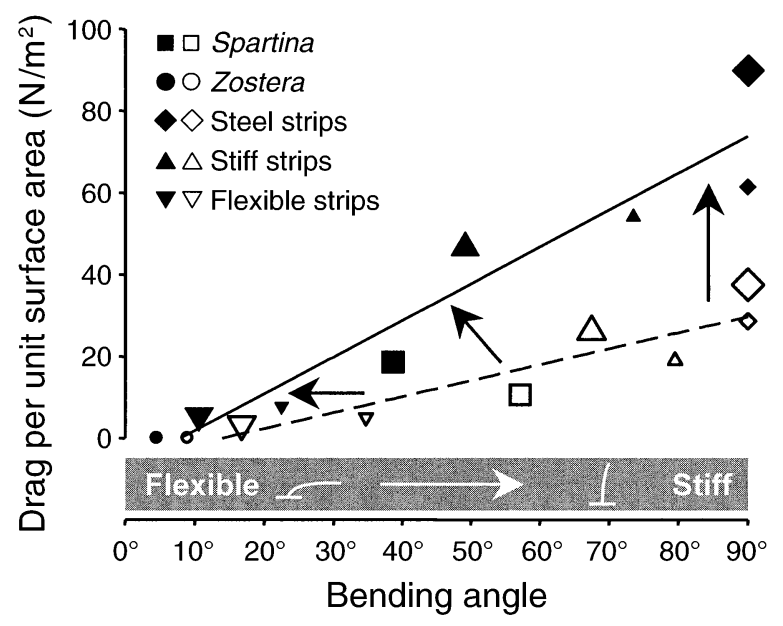

FIG. 5. The relation between bending of the leaves and the drag per unit of frontal plant surface area $\left(F_{\mathrm{d}}^{\prime} ; \mathrm{N} / \mathrm{m}^{2}\right)$. Bending is indicated as the angle from the horizontal $(\alpha)$, meaning that nonbending leaves are $90^{\circ}$ to the horizontal, whereas fully bent leaves approach $0^{\circ}$. Small and large diamond and triangle symbols represents strips of $100 \mathrm{~mm}$ and $200 \mathrm{~mm}$, respectively, and open and solid symbols indicate measurements at a velocity of 240 and $370 \mathrm{~mm} / \mathrm{s}$, respectively. Water height in the unidirectional flow flume was 400 $\mathrm{mm}$ above the sediment. The regression for the high velocity was $F_{\mathrm{d}}^{\prime}=0.898 \alpha-7.13\left(R^{2}=0.91\right)$, and for the low velocity, $F_{\mathrm{d}}^{\prime}=0.391 \alpha-5.43\left(R^{2}=0.85\right)$. By combining leaves of real plants with artificial leaves, the figure clarifies the general mechanism. Arrows indicate how enhanced velocity results in a strong increase in drag for stiff objects, whereas drag avoidance by reconfiguration increases with increasing flexibility. For Zostera, the drag was below the detection limit of the force transducer (i.e., $F_{\mathrm{d}}^{\prime}$ approached 0 ).

both the drag per unit surface area and bending increase with increasing current velocities.

2) Enhanced shoot length does not result in a lot of extra drag force at the base of the stem, provided that the shoots are flexible enough to compensate for the extra leaf length by stronger bending (e.g., compare drag for 100 and $200 \mathrm{~mm}$ long flexible strips).

3) For stiff structures $\left(\alpha=90^{\circ}\right)$, extra shoot length does enhance the drag per unit surface area, as less surface area will be located in the boundary layer where velocities are lower (i.e., compare the drag of nonbending 200 vs. $100 \mathrm{~mm}$ long steel strips). The importance of this effect will depend on the size of the boundary layer relative to the shoot length.

The force at the base of the stem increases with a power $\beta$ over current velocity (see Eq. 2). For unidirectional flow, $\beta$ was found to range between 1 and 2 (Table 2), depending on the flexibility of the shoot. For both the plant mimics and real plants, we observed an exponential relationship ( $\left.\alpha=90 e^{s U}\right)$ between bending of the shoots $(\alpha=$ angle of the shoot with the horizontal) and current velocity $(U ; \mathrm{mm} / \mathrm{s})$, with the value of $s$ depending on the stiffness of the shoot (Table $2)$. The value of $s$ goes from -0.0091 for the most flexible leaves (i.e., smallest $\alpha$ at $U_{\max }$ ) asymptotically toward 0 for completely stiff leaves (i.e., $\alpha$ is always $90^{\circ}$ ). The most flexible (artificial) plants bend easily with increasing current velocity (bending of Zostera $>$ $200 \mathrm{~mm}$ long flexible strips $>100 \mathrm{~mm}$ long flexible strips $>$ Spartina $>200 \mathrm{~mm}$ long stiff strips; see $s$ and $\alpha$ at $U_{\max }$ in Table 2), whereas less flexible (artificial) plants bend little (100 mm long stiff strips) or not (100 and $200 \mathrm{~mm}$ long steel strips). In agreement with the general theoretical background, the value of $\beta$ was around 2 for the very stiff (artificial) plants, whereas $\beta$ was lowest for the plant species that had the strongest reconfiguration by bending (Table 2). The relationship between drag and shoot stiffness as found in the unidirectional flow flume, was confirmed by observations in the wave flume (Fig. 6). Once again, drag was higher for the relatively stiff Spartina shoots than for the more flexible Zostera shoots, and this difference increased with wave energy (i.e., divergent lines Fig. 6) which is proportional to the square of wave height (Eq. 4).

\section{DISCUSSION}

The importance of ecosystem engineering and its possible consequences for ecosystem functioning are nowadays well recognized (Jones et al. 1994, 1997, Crooks 2002). However, remarkably little work has been done on the traits involved in ecosystem engineering and costs and benefits associated with these traits. Using intertidal coastal vegetation as a model system, we compared two autogenic ecosystem engineers (Spartina anglica and Zostera noltii) that share the same habitat, but that vary in the extent to which they modify abiotic conditions. In this study we concentrated on costs and benefits associated with shoot

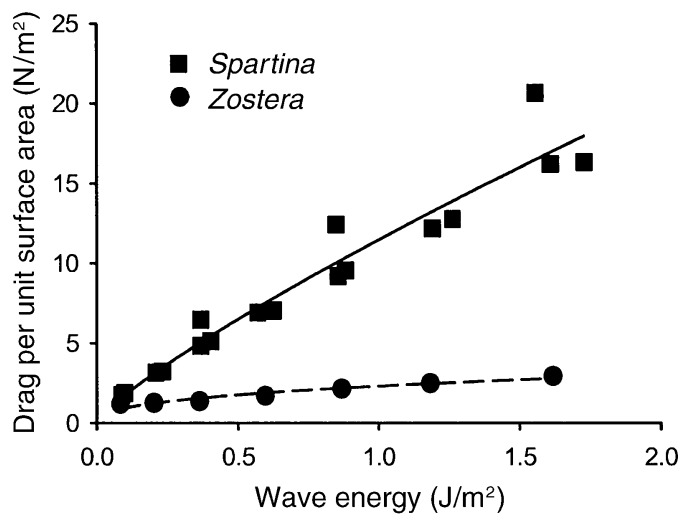

FIG. 6. The relation between wave energy $\left(E ; \mathrm{J} / \mathrm{m}^{2}\right)$ and the maximum drag per unit of frontal plant surface area $\left(F_{\mathrm{d}}^{\prime} ; \mathrm{N} / \mathrm{m}^{2}\right)$. Wave energy was calculated from wave height $(H ; \mathrm{m})$, using Eq. 4: $E=(1 / 8) \rho g H^{2}$, where $\rho$ is the density of seawater $\left(1025 \mathrm{~kg} / \mathrm{m}^{3}\right)$ and $g$ is the gravity acceleration $\left(9.8 \mathrm{~m} / \mathrm{s}^{2}\right)$. In wave conditions, the drag will show a sinusoidal fluctuation over time, as waves pass by. We only show the absolute value for the maximum drag that the plants experienced. Water height in the wave flume was $120 \mathrm{~mm}$ above the sediment. The regression for Spartina was $F_{\mathrm{d}}^{\prime}=$ $11.32\left(E^{0.790}\right)\left(R^{2}=0.97\right)$, and for Zostera, $F_{\mathrm{d}}^{\prime}=2.22\left(E^{0.319}\right)$ $\left(R^{2}=0.88\right)$. 
stiffness, which we expected to be the main trait that determines the ecosystem engineering strategy of these species. Wave attenuation was used as proxy for ecosystem engineering capacity; drag caused by waves and currents as proxy for the costs associated to this ecosystem engineering (detailed rationale in Materials and methods: Using drag as proxy for costs and wave attenuation as proxy for benefits: a rationale). Because hydrodynamic forces resulting from tidal currents and/ or waves differ from marsh to marsh, the flume studies were aimed at identifying generally applicable mechanisms, using flume conditions dimensioned to typical scales observed in northwestern European estuarine marshes. Our results indicate that Spartina anglica is able to modify its physical environment by reducing hydrodynamic energy from waves, at the cost of relatively large drag forces. Zostera noltii, on the other hand, was found to be more a stress-avoiding species in that it minimizes drag forces but consequently has a much lower capacity to reduce wave energy. Shoot stiffness was identified as the most significant plant trait involved in this trade-off. The conclusion derived from wave attenuation also applies to unidirectional flow, as the lack of bending by Spartina-like stiff shoots results both in a high drag and in a large volume where current velocities will be reduced, whereas bending by Zostera-like flexible shoots results both in a low drag and in a minimal volume of low flow. To our knowledge, the present study is one of the first to present evidence for trade-offs related to traits involved in autogenic ecosystem engineering (i.e., based on a survey of 347 papers that cite Jones et al. 1994).

The contrasting shoot stiffness of Zostera noltii and Spartina anglica enables both species to successfully cope with their hydrodynamic environment and matches well with the physiological requirements and growth strategy of both species. Being flexible, Zostera noltii reduces the drag-related costs relative to Spartina anglica, losing the ability of maximizing sediment trapping. Sediment trapping can be advantageous as a source of nutrients to Zostera (e.g., see Touchette and Burkholder 2000, Koch 2001). However, a too high sedimentation rate would reduce the available habitat by increasing the elevation outside the range suitable for growth of Zostera noltii (illustrated for Zostera marina in De Jonge et al. 2000, De Jonge and De Jong 2002). Being flexible is also advantageous for Zostera noltii by allowing for waving of seagrass leaves (Ackerman and Okubo 1993, Ghisalberti and Nepf 2002). This so-called monami effect is important to obtain a mixing layer instead of a boundary layer on top of the seagrass meadow, which provides seagrass leaves with sufficient $\mathrm{CO}_{2}$ and dissolved nutrients during inundation. Flexible shoots are also beneficial to seagrass leaves in preventing the risk of desiccation during low water periods in intertidal areas, as bent plants can remain wet from water present at the micro relief on top of the sediment (Van Katwijk 2000). But, similar as in macroalgae, being flexible may reduce light interception and expose leaves to lower velocities as are present nearer to the benthic boundary layer (e.g., see Stewart 2004, and references therein). For Spartina, a typical salt-marsh plant, inundation limits its growth. That is, Spartina plants require long enough low-tide periods to survive, and in contrast to Zostera, Spartina is not able to take up nutrients from the water column (Bouma et al. 2002). Compared to most salt-marsh species, Spartina has a large range of elevations where it can be dominant (De Leeuw et al. 1994). This capacity is closely related to sediment trapping by the plants, which results not only in increased local elevation, but also in better aeration of soils. It requires investment in building stiff stems and solid anchoring, and entails risks of breaking and uprooting.

The building of stiff stems like those of Spartina is not only determined by the biomass investment in the stem, but also depends on how the biomass is distributed within the stem. The latter is generally expressed as the second moment of area $\left(I ; \mathrm{m}^{4}\right.$; Wainwright et al. 1976). The stems of Spartina have the shape of a hollow tube for which the second moment of area is calculated as $I=1 / 4 \pi\left(R_{\text {out }}^{4}-R_{\text {in }}^{4}\right)$, with $R_{\text {out }}$ being the radius of the stem and $R_{\text {in }}$ being the radius of the hollow space inside the stem. The second moment of area for the relatively flat Zostera shoots should be calculated as $I$ $=(1 / 12) L_{\text {width }} L_{\text {diam }}^{3}$, with $L_{\text {width }}$ being the leaf width and $L_{\text {diam }}$ being the leaf diameter. To obtain a measure of the overall flexural stiffness of a structure, the second moment of area $(I)$ must be multiplied with the elasticity modulus $\left(E ; \mathrm{N} / \mathrm{m}^{2}\right)$, which is a measure for the resistance of material to deformation (Wainwright et al. 1976). A few simple measurements show that the second moment of area for Spartina and Zostera are around $3 \times 10^{-11}$ and $1 \times 10^{-15}$, respectively. These data imply that even in case both species are constructed from material with a similar resistance to deformation (i.e., similar $E$ ), the overall flexural stiffness will be much larger in Spartina than Zostera due to the shape of the structures.

The trade-offs related to the engineering abilities of Spartina anglica and Zostera noltii offer additional mechanistic understanding of the extent to which these autogenic ecosystem engineers are able to spread, and hence to the spatial distribution of the species. It has been demonstrated that hydrodynamic forces play a dominant role in the establishment, survival and expansion of plants in the pioneer zone of the marsh (e.g., see Bruno 2000, Houwing 2000, Robbins and Bell 2000, van Katwijk and Hermus 2000). The drag associated with stiff Spartina shoots limits how far out Spartina can grow downwards along the elevational gradient. Relatively low and more exposed areas where hydrodynamic forces are too strong for the establishment of Spartina, will be available to drag-minimizing species such as Zostera noltii. However, within the mudflat area where Spartina can establish, the accel- 
erated sediment trapping will transform this area gradually to a system that no longer can be inhabited by Zostera. This ecosystem engineering mechanism explains the occurrence of sharp transitions between Spartina and Zostera, which is in accordance with the hypothesis of Wilson and Agnew (1992) that ecosystem engineering generally lead to sharp spatial boundaries.

Wave attenuation and drag were used as proxies to analyze trade-offs related to ecosystem engineering strategies. Both processes have been studied for higher plants, but generally independently of each other. For example, the effect of seagrasses and salt-marsh species on hydrodynamics have been studied extensively, with emphasis on unidirectional flow (e.g., see Leonard and Luther 1995, Allen 2000, Verduin and Backhaus 2000, Koch 2001, Abdelrhman 2003, and references therein) and less work on wave attenuation (see Fonseca and Cahalan 1992, Yang 1998, Koch and Gust 1999, Moller et al. 1999). To our knowledge, a direct demonstration of the combined effect of plant stiffness and shoot density on wave attenuation (Fig. 3) has not been shown before. Although direct comparisons among papers are hampered by differences in shoot traits, vegetation densities and experimental setups, present results (Table 1) are in line with available literature data (e.g., $40 \%$ reduction in wave energy per meter of seagrass bed; Fonseca and Cahalan 1992). Consequences of shoot morphologies for withstanding hydrodynamic drag is poorly studied in plant species (e.g., see Ennos 1999, Sand-Jensen 2003 and references therein), especially when compared to the large body of work available for macroalgae (e.g., see review of Denny and Gaylord 2002). A higher drag with a stronger dependence on current velocity in stiff vegetations compared to flexible vegetations (Table 2) is in agreement with the theory and earlier observations. Present estimates of $\beta$ also agree well with the literature $(\sim 1$ for reconfiguring Ranunculus fluitans, Usherwood et al. 1997; 2 for nonreconfiguring Fontinalis antipyretica, Biehle et al. 1998; between 0.76 and 1.33 for five reconfiguring submerged freshwater macrophytes, Sand-Jensen 2003; between 1.24 and 1.70 for plastic strips with contrasting stiffness, Sand-Jensen 2003). In general, a more integrated approach towards hydrodynamic studies for higher plants would enhance our understanding of growth strategies through underlying trade-offs.

The number of studies that put ecosystem engineering in a more evolutionary context is still scarce (Jones et al. 1997), although this topic is currently strongly gaining interest (Day et al. 2003, Odling-Smee et al. 2003). While the comparative approach we used does not permit to directly address evolutionary questions, our results allow us to make some speculations on the adaptive nature of shoot stiffness. In case of autogenic ecosystem engineers, where organisms change the environment via their own physical structures, it can be assumed that ecosystem engineering represents merely a side effect of those physical structures. The presence of less dominant pioneer species that have a more open vegetation structure (e.g., Salicornia) or less stiff shoots (e.g., Puccinellia), which in northwestern European salt marshes both occur at approximately similar elevations as Spartina, suggest that the shoot morphology of Spartina contributes to its dominance. The enhanced accretion that results from the reduction of hydrodynamic energy can enhance growth of Spartina plants (Hemminga et al. 1998). Due to the horizontal distance within vegetation needed to attenuate waves (Fig. 4), wave attenuation by stiff shoots does not necessarily offer advantages to the individual shoot that causes the dissipation of the wave energy. However, in a clonal species like Spartina, individuals can be large enough to benefit from wave attenuation. Hence, the clone as a whole could benefit from ecosystem engineering by the more exposed tillers in the sense of an extended phenotype (sensu Dawkins 1982). It would be interesting to test if ecosystem engineering strategies that have an explicit spatial dependence as is the case in wave attenuation, are restricted to or occur predominantly in clonal species. Division of labor is a well-documented process in clonal species (e.g., see De Kroon et al. 1998, Charpentier and Stuefer 1999, Van Kleunen and Stuefer 1999, Pennings and Callaway 2000). In general, the vascular conductivity of stolon internodes is regarded to play a crucial role in the degree of specialization and cooperation within clonal plants (Stuefer et al. 1998). The present example of Spartina, where the most exposed shoots attenuate the majority of the hydrodynamic energy, enhancing accretion of sediment and nutrients in the rest of the clone, suggests that other processes than energy flux can be important in the division of labor.

In conclusion, we studied two autogenic engineers that modify the physical environment to a different extent. Our study demonstrated that simple physical relationships (Figs. 3, 5, and 6) govern trade-offs associated with traits that determine the extent to which autogenic ecosystem engineers can modify the physical environment. Insight in physical constraints has been shown to be particularly important for understanding how organisms in general function within their environment (e.g., West et al. 1997, 1999, 2001). Uncovering simple cost-benefit relationships that govern the interactions between organisms and their abiotic environment will also be crucial in further developing a general theory of (autogenic) ecosystem engineering.

\section{ACKNOWLEDGMENTS}

We thank Kees Koree and Wim Talen for their support of the flume experiments performed at WL|Delft Hydraulics, Bas Koutstaal and Jos van Soelen for their help in the experiments at NIOO-CEME, and Joop van de Pot for providing us with a suitable force transducer. We are especially grateful to Mark Denny, Mark Bertness, Don Strong's group, and two anonymous reviewers for their positive critical comments on earlier versions of this paper. This is publication 3468 NIOOKNAW Netherlands Institute of Ecology. 


\section{REFERENCES}

Abdelrhman, M. 2003. Effect of eelgrass Zostera marina canopies on flow and transport. Marine Ecology Progress Series 248:67-83.

Ackerman, J. D., and A. Okubo. 1993. Reduced mixing in a marine macrophyte canopy. Functional Ecology 7:305309.

Alben, S., M. Shelley, and J. Zhang. 2002. Drag reduction through self-similar bending of a flexible body. Nature 420: 479-481.

Allen, J. R. L. 2000. Morphodynamics of Holocene salt marshes: a review sketch from the Atlantic and southern North Sea coast of Europe. Quaternary Science Reviews 19:1155-1231.

Almasi, M. N., C. M. Hoskin, J. K. Reed, and J. Milo. 1987. Effects of natural and artificial Thalassia on rates of sedimentation. Journal of Sedimentary Petrology 57:901-906.

Bertness, M. D., and S. D. Hacker. 1994. Physical stress and positive associations among marsh plants. American Naturalist 144:363-372.

Bertness, M. D., and G. H. Leonard. 1997. The role of positive interactions in communities: lessons from intertidal habitats. Ecology 78:1976-1989.

Biehle, G., T. Speck, and H. C. Spatz. 1998. Hydrodynamics and biomechanics of the submerged water moss Fontinalis antipyretica: a comparison of specimens from habitats with different flow velocities. Botanica Acta 111:42-50.

Bouma, T. J., M. B. De Vries, E. Low, L. Kusters, P. M. J. Herman, I. C. Tánczos, S. Temmerman, A. Hesselink, P. Meire, and S. van Regenmortel. 2005. Flow hydrodynamics on a mudflat and in salt marsh vegetation: identifying general relationships for habitat characterisations. Hydrobiologia 540:259-274.

Bouma, T. J., J. Stapel, J. van der Heiden, B. Koutstaal, J. van Soelen, and L. van Ijzerloo. 2002. Relative importance of macrophyte leaves for nitrogen uptake from flood water in tidal salt marshes. Marine Ecology Progress Series 240: 93-104.

Bruno, J. F. 2000. Facilitation of cobble beach plant communities through habitat modification by Spartina alterniflora. Ecology 81:1179-1192.

Bruno, J. F., J. J. Stachowicz, and M. D. Bertness. 2003. Inclusion of facilitation into ecological theory. Trends in Ecology and Evolution 18:119-125.

Carrington, E. 1990. Drag and dislodgment of an intertidal macroalga: consequences of morphological variation in Mastocarpus papillatus Kutzing. Journal of Experimental Marine Biology and Ecology 139:185-200.

Castellanos, E. M., M. E. Figueroa, and A. J. Davy. 1994. Nucleation and facilitation in salt-marsh succession: interactions between Spartina maritima and Arthrocnemum perenne. Journal of Ecology 82:239-248.

Charpentier, A., and J. F. Stuefer. 1999. Functional specialization of ramets in Scirpus maritimus: splitting the tasks of sexual reproduction, vegetative growth, and resource storage. Plant Ecology 141:129-136.

Crooks, J. A. 2002. Characterizing ecosystem-level consequences of biological invasions: the role of ecosystem engineers. Oikos 97:153-166.

Dawkins, R. 1982. The extended phenotype. Oxford University Press, Oxford, UK.

Day, R. L., K. N. Laland, and J. Odling-Smee. 2003. Rethinking adaptation: the niche-construction perspective. Perspectives in Biology and Medicine 46:80-95.

De Jonge, V. N., and D. J. De Jong. 2002. Ecological restoration in coastal areas in the Netherlands: concepts, dilemmas and some examples. Hydrobiologia 478:7-28.

De Jonge, V. N., D. J. De Jong, and M. M. Van Katwijk. 2000. Policy plans and management measures to restore eelgrass (Zostera marina L.) in the Dutch Wadden Sea. Helgoland Marine Research 54:151-158.

De Kroon, H., E. van der Zalm, J. W. A. van Rheenen, A. van Dijk, and R. Kreulen. 1998. The interaction between water and nitrogen translocation in a rhizomatous sedge (Carex flacca). Oecologia 116:38-49.

De Leeuw, J., L. P. Apon, P. M. J. Herman, W. De Munck, and W. G. Beeftink. 1994. The response of salt-marsh vegetation to tidal reduction caused by the Oosterschelde storm-surge barrier. Hydrobiologia 283:335-353.

Denny, M. 1988. Biology and the mechanics of wave-swept environment. Princeton University Press, Princeton, New Jersey, USA.

Denny, M. 1999. Are there mechanical limits to size in waveswept organisms? Journal of Experimental Biology 202: 3463-3467.

Denny, M., and B. Gaylord. 2002. The mechanics of waveswept algae. Journal of Experimental Biology 205:13551362 .

Denny, M., B. Gaylord, B. Helmuth, and T. Daniel. 1998. The menace of momentum: dynamic forces on flexible organisms. Limnology and Oceanography 43:955-968.

Ennos, A. R. 1999. The aerodynamics and hydrodynamics of plants. Journal of Experimental Biology 202:3281-3284.

Fonseca, M. S., and J. A. Cahalan. 1992. A preliminary evaluation of wave attenuation by four species of seagrass. Estuarine Coastal and Shelf Science 35:565-576.

Fonseca, M. S., J. S. Fisher, J. C. Zieman, and G. W. Thayer. 1982. Influence of the seagrass Zostera marina L. on current flow. Estuarine Coastal and Shelf Science 15:351-364.

Gacia, E., T. C. Granata, and C. M. Duarte. 1999. An approach to measurement of particle flux and sediment retention within seagrass (Posidonia oceanica) meadows. Aquatic Botany 65:255-268.

Gambi, M. C., A. R. M. Nowell, and P. S. Jumars. 1990. Flume observations of flow dynamics in Zostera marina (eelgrass) beds. Marine Ecology Progress Series 61:159169.

Gaylord, B. 2000. Biological implications of surf-zone complexity. Limnology and Oceanography 45:174-188.

Ghisalberti, M., and H. M. Nepf. 2002. Mixing layers and coherent structures in vegetated aquatic flows. Journal of Geophysical Research-Oceans 107(C2):1-11.

Granata, T. C., T. Serra, J. Colomer, X. Casamitjana, C. M. Duarte, and E. Gacia. 2001. Flow and particle distributions in a nearshore seagrass meadow before and after a storm. Marine Ecology Progress Series 218:95-106.

Grime, J. P. 1977. Evidence for the existence of three primary strategies in plants and its relevance to ecological and evolutionary theory. American Naturalist 111:1169-1194.

Grime, J. P. 1979. Plant strategies and vegetation processes. John Wiley and Sons, Chichester, UK.

Grime, J. P. 1988. Critique of the triangular model of primary plant strategies-comment. Ecology 69:1618-1620.

Grime, J. P., and J. M. L. Mackey. 2002. The role of plasticity in resource capture by plants. Evolutionary Ecology 16: 299-307.

Hemminga, M. A., J. van Soelen, and Y. E. M. Maas. 1998. Biomass production in pioneer Spartina anglica patches: evidence for the importance of seston particle deposition. Estuarine Coastal and Shelf Science 47:797-805.

Houwing, E. J. 2000. Morphodynamic development of intertidal mudflats: consequences for the extension of the pioneer zone. Continental Shelf Research 20:1735-1748.

Jones, C. G., J. H. Lawton, and M. Shachak. 1994. Organisms as ecosystem engineers. Oikos 69:373-386.

Jones, C. G., J. H. Lawton, and M. Shachak. 1997. Positive and negative effects of organisms as physical ecosystem engineers. Ecology 78:1946-1957. 
Koch, E. W. 2001. Beyond light: physical, geological, and geochemical parameters as possible submersed aquatic vegetation habitat requirements. Estuaries 24:1-17.

Koch, E. W., and G. Gust. 1999. Water flow in tide- and wave-dominated beds of the seagrass Thalassia testudinum. Marine Ecology Progress Series 184:63-72.

Leonard, L. A., and M. E. Luther. 1995. Flow hydrodynamics in tidal marsh canopies. Limnology and Oceanography 40 : 1474-1484.

Madsen, J. D., P. A. Chambers, W. F. James, E. W. Koch, and D. F. Westlake. 2001. The interaction between water movement, sediment dynamics and submersed macrophytes. Hydrobiologia 444:71-84.

Moller, I., T. Spencer, J. R. French, D. J. Leggett, and M. Dixon. 1999. Wave transformation over salt marshes: a field and numerical modelling study from north Norfolk, England. Estuarine Coastal and Shelf Science 49:411-426.

Odling-Smee, F. J., K. N. Laland, and M. W. Feldman. 2003. Niche construction: the neglected process in evolution. Princeton University Press, Princeton, New Jersey, USA.

Pennings, S. C., and R. M. Callaway. 2000. The advantages of clonal integration under different ecological conditions: a community-wide test. Ecology 81:709-716.

Pianka, E. R. 1970. On $r$ - and $K$-selection. American Naturalist 104:592-597.

Reichman, O. J., and E. W. Seabloom. 2002. The role of pocket gophers as subterranean ecosystem engineers. Trends in Ecology and Evolution 17:44-49.

Robbins, B. D., and S. S. Bell. 2000. Dynamics of a subtidal seagrass landscape: seasonal and annual change in relation to water depth. Ecology 81:1193-1205.

Sanchez, J. M., D. G. SanLeon, and J. Izco. 2001. Primary colonisation of mudflat estuaries by Spartina maritima (Curtis) Fernald in northwest Spain: vegetation structure and sediment accretion. Aquatic Botany 69:15-25.

Sand-Jensen, K. 2003. Drag and reconfiguration of freshwater macrophytes. Freshwater Biology 48:271-283.

Shi, Z., J. S. Pethick, and K. Pye. 1995. Flow structure in and above the various heights of a salt-marsh canopy-a laboratory flume study. Journal of Coastal Research 11: 1204-1209.

Stewart, H. L. 2004. Hydrodynamic consequences of maintaining an upright posture by different magnitude of stiffness and buoyancy in the tropical alga Turbinaria ornate. Journal of Marine Systems 49:157-167.

Stuefer, J. F., H. J. During, and F. Schieving. 1998. A model on optimal root-shoot allocation and water transport in clonal plants. Ecological Modelling 111:171-186.
Touchette, B. W., and J. M. Burkholder. 2000. Review of nitrogen and phosphorus metabolism in seagrass. Journal of Experimental Marine Biology and Ecology 250:133167.

Usherwood, J. R., A. R. Ennos, and D. J. Ball. 1997. Mechanical and anatomical adaptations in terrestrial and aquatic buttercups to their respective environments. Journal of Experimental Botany 48:1469-1475.

Van Katwijk, M. M. 2000. Possibilities for restoration of Zostera marina beds in the Dutch Wadden Sea. Dissertation. Catholic (Radboud) University, Nijmegen, The Netherlands.

Van Katwijk, M. M., and D. C. R. Hermus. 2000. Effects of water dynamics on Zostera marina: transplantation experiments in the intertidal Dutch Wadden Sea. Marine Ecology Progress Series 208:107-118.

Van Kleunen, M., and J. F. Stuefer. 1999. Quantifying the effects of reciprocal assimilate and water translocation in a clonal plant by the use of steam-girdling. Oikos 85:135145.

Verduin, J. J., and J. O. Backhaus. 2000. Dynamics of plantflow interactions for the seagrass Amphibolis antarctica: field observations and model simulations. Estuarine Coastal and Shelf Science 50:185-204.

Vogel, S. 1994. Life in moving fluids: the physical biology of flow. Princeton University Press, Princeton, New Jersey, USA.

Wainwright, S. R., W. D. Biggs, J. D. Currey, and J. M. Gosline. 1976. Mechanical design in organisms. Wiley, New York, New York, USA.

West, G. B., J. H. Brown, and B. J. Enquist. 1997. A general model for the origin of allometric scaling laws in biology. Science 276:122-126.

West, G. B., J. H. Brown, and B. J. Enquist. 1999. A general model for the structure and allometry of plant vascular systems. Nature 400:664-667.

West, G. B., J. H. Brown, and B. J. Enquist. 2001. A general model for ontogenetic growth. Nature 413:628-631.

Widdows, J., and M. Brinsley. 2002. Impact of biotic and abiotic processes on sediment dynamics and the consequences to the structure and functioning of the intertidal zone. Journal of Sea Research 48:143-156.

Wilson, J. B., and D. Q. Agnew. 1992. Positive-feedback switches in plant communities. Advances in Ecological Research 23:263-336.

Yang, S. L. 1998. The role of Scirpus marsh in attenuation of hydrodynamics and retention of fine sediment in the Yangtze estuary. Estuarine Coastal Shelf Science 47:227233. 